\title{
Impact of the Number of Dissected Axillary Lymph Nodes on Survival in Breast Cancer Patients
}

\author{
Emad Eldin Nabil', Ahmed M Maklad ${ }^{2,3}$, Ashraf Elyamany ${ }^{4,5^{*}}$, Emad Gomaa $^{6}$ and Moamen M Ali ${ }^{3,7}$
}

${ }^{1}$ Clinical Oncology and Nuclear Medicine Department, Sohag University Hospitals, Egypt

${ }^{2}$ Clinical Oncology and Nuclear Medicine Department, Sohag University Hospitals, Egypt

${ }^{3}$ King Fahad Medical City, Riyadh, KSA

${ }^{4}$ Medical Oncology Department, SECl, Assiut University, Egypt

${ }^{5}$ King Saud Medical City, Riyadh, KSA

${ }^{6}$ General Surgery Department, Sohag University Hospitals, Egypt

${ }^{7}$ Medical Physics, Radiation Oncology Department, SECl, Assiut University, Egypt

*Corresponding author: Ashraf Elyamany, Medical Oncology Department, SECl, Assiut University, Egypt; King Saud Medical City, Riyadh, KSA

\begin{abstract}
Background: For patients with breast cancer, axillary dissection was a standard treatment, especially with patient with positive metastases in the sentinel nodes. For some patients axillary dissection might be over-treatment, including those who have had a mastectomy. Especially with the new trend of many radiation-therapy centers, provide radiation-therapy for any number of positive lymph nodes. The aim of our work is to evaluate the impact of number of dissected axillary Lymph Nodes (LN), on Overall Survival (OS) and Progression Free Survival (PFS) in breast cancer patients.
\end{abstract}

Methods: This is a retrospective study done in Sohag University hospitals between periods $1 / 2008$ till 12/2014. One hundred and three patients diagnosed with breast cancer were reviewed regarding number of axillary lymph nodes dissected in correlation to progression free survival, overall survival. We divided the patients into two groups according to number of dissected lymph nodes more than 10 LNs (73 patients or less than ten LN (30 patients)). The patients were categorized into N0 (No LN positive), N1 (1-3 LN positive), N2 (3-9LN positive) in both groups, and N3 in first group only as it is more than $10 \mathrm{LN}$ positive.

Results: Median PFS for patients having more than 10 LN excised was for N0, N1, N2, N3 5.19, 4.77, 4.14, 3.69 years respectively, while in the group with less than 10 LN excised PFS was 4.5, 4.14, 4.08 years respectively with no significant difference between both groups $P=0.290$. As regard median OS for patients having more than $10 \mathrm{LN}$ excised was for N0, N1, N2, N3 5.57, 5.94, 4.97, 4.61 years respectively while in the other group having less than $10 \mathrm{LN}$ excised OS was $5.4,5.14,5.14$ years respectively with $\mathrm{P}=$ 0.117 . Regarding Lymphedema There was highly significant difference between both arms $p$ value 0.000 , with higher grades in arm I (moderate 17 cases and 6 cases severe edema).

Conclusions: We found no significant OS or PFS differences with higher LN dissection compared with less LN dissection, but this needs further prospective studies. Quality of life was better for the less axillary dissected patients due to significantly lower incidence of advanced grade lymphedema.

\section{Introduction}

Axillary lymph nodes involvement is one of the most important factors for cancer staging, treatment, and prognosis. Surgical excision of primary tumor plus axillary lymph nodes dissection has been considered as a part of breast cancer the standard management [1]. Axillary Staging is an important step in breast cancer treatment. Axillary lymph nodes status is a significant prognostic variable, rather than therapeutic in operable breast cancer. It considered the most important predictor of recurrence and survival. The number of involved

Citation: Nabil EE, Maklad AM, Elyamany A, Gomaa E, Ali MM (2019) Impact of the Number of Dissected Axillary Lymph Nodes on Survival in Breast Cancer Patients. Int J Oncol Res 2:015. doi. org/10.23937/2643-4563/1710015

Accepted: June 03, 2019; Published: June 05, 2019

Copyright: (C) 2019 Nabil EE, et al. This is an open-access article distributed under the terms of the Creative Commons Attribution License, which permits unrestricted use, distribution, and reproduction in any medium, provided the original author and source are credited. 
lymph nodes with metastasis, but not the total number of dissected lymph node also has a prognostic importance, [2,3]. There is no clear data about the adequate number of lymph node to be dissected. The consensus was to dissect (levels I and II) for all women with invasive breast cancer and at least 10 axillary lymph nodes to be able to apply TNM staging. With the new trend of treatment, the number of the lymph node dissected will not affect further treatment plan as regard adjuvant treatment, especially after the new recommendations for adjuvant radiotherapy even if single lymph node was involved as per Danish, and EORTC studies [4,5]. Thinking about the future, understanding host biology as tumor molecular profiles, stromal microenvironment and patient genetic and immune parameters may replace our need for axillary dissection as an indicator for axillary radiation [6]. National Surgical Adjuvant Breast and Bowel Project (NSABP) B-04 study showed that patients with a predicted risk of harboring axillary disease of about $40 \%$, developed local recurrences in that region only $20 \%$ of the time if axillary lymph node dissection was not done. Additionally, incidental axillary irradiation may also have helped to reduce the risk of recurrence $[7,8]$.

For patients with clinically negative axilla who will do mastectomy, NCCN panel suggests that it can be replaced by radiation to axilla without compromising axillary recurrences, [9].

10-year overall survival for patients treated with sentinel lymph node dissection alone was non-inferior to those treated with axillary lymph node dissection in updated data of ACOSOG Z0011. This is not supporting use of axillary lymph node dissection in patients with T1 or T2 invasive breast cancer, without palpable axillary adenopathy, and 1 or 2 sentinel lymph nodes containing metastases [10]. Also in AMAROS study updated 10 years which was published in SABC (San Antonio Breast Cancer) 2018 showed axillary lymph node dissection and axillary radiotherapy after a positive sentinel node provide comparable distant metastasis-free survival and overall survival for patients with T1-2 primary breast cancer and no palpable lymphadenopathy with less morbidity in axillary radiotherapy arm [11].

Based on the previous data we decided to retrospectively review the patients with inadequate axillary lymph nodes dissection seen at our hospital and to compare the results with other patients who underwent adequate lymph nodes dissection.

\section{Aim of the Study}

To evaluate the impact of the number of dissected axillary Lymph Nodes (LN), on Overall Survival (OS) and Disease Free Survival (DFS) in breast cancer patients.

\section{Materials and methods}

This is a retrospective study done in Sohag University
Table 1: Demographic data in study group.

\begin{tabular}{|l|l|}
\hline Item & Descriptive \\
\hline 1-Age "yrs." & $49.43 \pm 10.51$ \\
\hline 2-Menopausal status: & \\
\hline$\bullet \quad$ Post & $48(46.6 \%)$ \\
\hline$\bullet \quad$ Pre & $55(53.4 \%)$ \\
\hline 3-Marital status: & \\
\hline$\bullet \quad$ Married & $95(92.2 \%)$ \\
\hline$\bullet \quad$ Widow & $4(3.9 \%)$ \\
\hline$\bullet \quad$ Single & $4(3.9 \%)$ \\
\hline
\end{tabular}

hospitals, Egypt between periods 1/2008 till 12/2014 for follow up ranging between (24-120) months. One hundred and three patients diagnosed with breast cancer were reviewed regarding the number of axillary lymph nodes dissected in correlation to progression free survival and overall survival. We divided the patients into two groups according to the number of dissected lymph nodes more than ten LN (73 patients) Arm 1 or less than 10 LNs dissected (30 patients) Arm 2. The patients were categorized into N0 (No LN positive), N1 (1-3 LN positive), N2 (3-9 LN positive), and N3 more than 10 LN positive in arm 1 and in arm 2 N4 (No LN positive), N5 (1-3 LN positive), and N6 (3-9 LN positive) whatever number of lymph nodes dissected as long less than 10 .

\section{Results}

Our study included one hundred and three patients diagnosed with breast cancer. Mean age of the included patients was $49.43 \pm 10.51$ years. $46.6 \%$ of the patients were postmenopausal and $53.4 \%$ were premenopausal. MRM was done in $79.6 \%$. T3 and T4 represent $82.65 \%$. N2and N3 was documented in $46.6 \%$. Extracapsular invasion was found in $33 \%$ of the patients. Systemic chemotherapy was given in $97.1 \%$ of cases. Adjuvant radiotherapy was given to chest wall plus peripheral lymphatics for $87.4 \%$ of the included patients. Demographic and Clinical data of all patients are represented in Table 1 and Table 2. Regarding clinical characteristics and therapeutic lines of both arms, it was more or less equally distributed except for extracapsular extension, which was higher in arm 1 ( $p$-value: 0.001), and HER2 status was over expressed more significantly in arm1 (p-value: 0.04 ) although it was known in $41.7 \%$ of the patients only. There was no significant difference as regard post-operative adjuvant chemotherapy, hormonal and radiotherapy volumes ( $P$ values respectively 0.102 , 0.558 , and 0.222 ) Table 3. Patients were reviewed regarding the number of axillary lymph nodes dissected in correlation to progression free survival, and overall survival and quality of life.

Disease free survival (DFS): Median DFS for patients having more than $10 \mathrm{LN}$ excised was 5.19, 4.77, 4.14, 3.69 years for N0, N1, N2, N3 respectively. While in the group with less than $10 \mathrm{LN}$ excised DFS was 4.5, $4.14,4.08$ years (for N4, N5, N6 respectively) with no 
Table 2: Clinical data in study group.

\begin{tabular}{|c|c|}
\hline Item & Descriptive \\
\hline \multicolumn{2}{|l|}{$1-$} \\
\hline IDC & $92(89.3 \%)$ \\
\hline Medullary & $4(3.9 \%)$ \\
\hline ILC & $7(6.8 \%)$ \\
\hline \multicolumn{2}{|l|}{ 2-Grade: } \\
\hline 1 & $2(1.9 \%)$ \\
\hline II & $95(92.2 \%)$ \\
\hline III & $6(5.8 \%)$ \\
\hline \multicolumn{2}{|c|}{ 1-Type of surgery: } \\
\hline MRM & $82(79.6 \%)$ \\
\hline BCS & $21(20.4 \%)$ \\
\hline \multicolumn{2}{|l|}{ 4-T: } \\
\hline$x$ & $6(5.8 \%)$ \\
\hline 1 & $6(5.8 \%)$ \\
\hline 2 & $63(61.2 \%)$ \\
\hline 3 & $22(21.4 \%)$ \\
\hline 4 & $6(5.8 \%)$ \\
\hline \multicolumn{2}{|c|}{ 5-LN number: } \\
\hline 0 & $14(13.6 \%)$ \\
\hline 1 & $17(16.5 \%)$ \\
\hline 2 & $24(23.3 \%)$ \\
\hline 3 & $18(17.5 \%)$ \\
\hline 4 & $10(9.7 \%)$ \\
\hline 5 & $14(13.6 \%)$ \\
\hline 6 & $6(5.8 \%)$ \\
\hline \multicolumn{2}{|c|}{ 6-Extracapsular invasion: } \\
\hline no & $45(43.7 \%)$ \\
\hline yes & $34(33.0 \%)$ \\
\hline unknown & $24(23.3 \%)$ \\
\hline 7-ER: & \\
\hline
\end{tabular}

\begin{tabular}{|c|c|}
\hline Positive & $64(62.1 \%)$ \\
\hline Negative & $38(36.9 \%)$ \\
\hline Unknown & $1(1.0 \%)$ \\
\hline \multicolumn{2}{|l|}{ 8-PR: } \\
\hline Positive & $53(51.5 \%)$ \\
\hline Negative & $48(46.6 \%)$ \\
\hline Unknown & $2(1.9 \%)$ \\
\hline \multicolumn{2}{|l|}{ 9- Her2-neu } \\
\hline Positive & $6(5.8 \%)$ \\
\hline Negative & $37(35.9 \%)$ \\
\hline Unknown & $60(58.3 \%)$ \\
\hline \multicolumn{2}{|c|}{ 10-Chemotherapy: } \\
\hline CMF & $7(6.8 \%)$ \\
\hline FAC & $61(59.2 \%)$ \\
\hline FEC & $28(27.2 \%)$ \\
\hline taxane based & $3(2.9 \%)$ \\
\hline Herceptin & $1(1.0 \%)$ \\
\hline No CTR & $3(2.9 \%)$ \\
\hline \multicolumn{2}{|l|}{ 11- Radiotherapy: } \\
\hline$C W+P L$ & $90(87.4 \%)$ \\
\hline $\mathrm{CW}$ & $7(6.8 \%)$ \\
\hline no Rth & $6(5.8 \%)$ \\
\hline \multicolumn{2}{|c|}{ 12-Hormonal treatment: } \\
\hline Tam & $55(53.4 \%)$ \\
\hline Als & $12(11.7 \%)$ \\
\hline Not given & $34(33.0 \%)$ \\
\hline Tam and Zoladex & $2(1.9 \%)$ \\
\hline \multicolumn{2}{|c|}{ 13-Type of progression: } \\
\hline Local & $3(2.9 \%)$ \\
\hline local and distant & $5(4.9 \%)$ \\
\hline distant & $31(30.1 \%)$ \\
\hline No progression & $64(62.1 \%)$ \\
\hline
\end{tabular}

Table 3: Relation between Clinical data with lymph node category in study group.

\begin{tabular}{|c|c|c|c|}
\hline Item & $\begin{array}{l}\mathrm{LN}=0,1,2,3 \\
" \mathrm{n}=73 "\end{array}$ & $\begin{array}{l}\mathrm{LN}=4,5,6 \\
" \mathrm{n}=30 "\end{array}$ & P-value \\
\hline \multicolumn{4}{|l|}{$1-$} \\
\hline IDC & $66(90.4 \%)$ & $26(86.7 \%)$ & $\mathrm{P}=0.7, \mathrm{~ns}$ \\
\hline Medullary & $3(4.1 \%)$ & $1(3.3 \%)$ & \\
\hline ILC & $4(5.5 \%)$ & $3(10 \%)$ & \\
\hline \multicolumn{4}{|l|}{ 2-Grade: } \\
\hline I & 0 & $2(6.7 \%)$ & $\mathrm{P}=0.07, \mathrm{~ns}$ \\
\hline II & $68(93.1 \%)$ & $27(90 \%)$ & \\
\hline III & $5(6.9 \%)$ & $1(3.3 \%)$ & \\
\hline \multicolumn{4}{|c|}{ 1-Type of surgery: } \\
\hline MRM & $58(79.5 \%)$ & $24(80 \%)$ & $P=0.95, n s$ \\
\hline BCS & $15(20.5 \%)$ & $6(20 \%)$ & \\
\hline
\end{tabular}




\begin{tabular}{|c|c|c|c|}
\hline \multicolumn{4}{|l|}{ 4-T: } \\
\hline$x$ & $3(4.1 \%)$ & $3(10 \%)$ & $\mathrm{P}=0.27, \mathrm{~ns}$ \\
\hline 1 & $5(6.9 \%)$ & $1(3.3 \%)$ & \\
\hline 2 & $42(57.5 \%)$ & $21(70 \%)$ & \\
\hline 3 & $17(23.3 \%)$ & $5(16.7 \%)$ & \\
\hline 4 & $6(8.2 \%)$ & 0 & \\
\hline \multicolumn{4}{|c|}{ 6-Extracapsular invasion: } \\
\hline no & $27(36.9 \%)$ & $18(60 \%)$ & $\mathrm{P}<0.001^{* *}$ \\
\hline yes & $32(43.9 \%)$ & $2(6.7 \%)$ & \\
\hline unknown & $14(19.2 \%)$ & $10(33.3 \%)$ & \\
\hline \multicolumn{4}{|l|}{ 7-ER: } \\
\hline Positive & $48(65.8 \%)$ & $16(53.3 \%)$ & $P=0.36, n s$ \\
\hline Negative & $24(32.9 \%)$ & $14(46.7 \%)$ & \\
\hline Unknown & $1(1.4 \%)$ & 0 & \\
\hline 8-PR: & $38(52.1 \%)$ & $15(50 \%)$ & $P=0.8, n s$ \\
\hline Positive & $34(46.5 \%)$ & $14(46.7 \%)$ & \\
\hline Negative & $1(1.4 \%)$ & $1(3.3 \%)$ & \\
\hline \multicolumn{4}{|l|}{ 9- Her2-neu } \\
\hline Positive & $6(8.2 \%)$ & 0 & $P=0.08, n s$ \\
\hline Negative & $29(39.7 \%)$ & $8(25.8 \%)$ & \\
\hline Unknown & $38(52.1 \%)$ & $22(74.2 \%)$ & \\
\hline \multicolumn{4}{|l|}{ 10-Chemotherapy: } \\
\hline CMF & $5(6.8 \%)$ & $2(6.7 \%)$ & $P=0.078, n s$ \\
\hline FAC & $47(64.4 \%)$ & $14(46.7 \%)$ & \\
\hline FEC & $14(19.2 \%)$ & $14(46.7 \%)$ & \\
\hline Taxane based & $3(4.1 \%)$ & 0 & \\
\hline Herceptin & $1(1.4 \%)$ & 0 & \\
\hline No CTR & $3(4.1 \%)$ & 0 & \\
\hline \multicolumn{4}{|l|}{ 11- Radiotherapy: } \\
\hline$C W+P L$ & $65(89.4 \%)$ & $25(83.3 \%)$ & $P=0.203, n s$ \\
\hline CW & $3(4.1 \%)$ & $4(13.3 \%)$ & \\
\hline no Rth & $5(6.8 \%)$ & $1(3.3 \%)$ & \\
\hline \multicolumn{4}{|c|}{ 12-Hormonal treatment: } \\
\hline Tam & $40(54.8 \%)$ & $15(50 \%)$ & $P=0.564, n s$ \\
\hline Als & $10(13.7 \%)$ & $2(6.6 \%)$ & \\
\hline Not given & $22(30.1 \%)$ & $12(40 \%)$ & \\
\hline Tam and Zoladex & $1(1.4 \%)$ & $1(3.3 \%)$ & \\
\hline
\end{tabular}

significant difference between both groups (P: 0.290) Figure 1 and Figure 2.

Overall Survival (OS): Median OS for patients having more than $10 \mathrm{LN}$ excised was 5.57, 5.94, 4.97, 4.61 years for N0, N1, N2, N3 respectively, while in the other group having less than $10 \mathrm{LN}$ excised OS was 5.4, 5.14, 5.14 years (for N4, N5, N6 respectively) with non-statistically significant difference (P: 0.117) Figure 3 and Figure 4. 


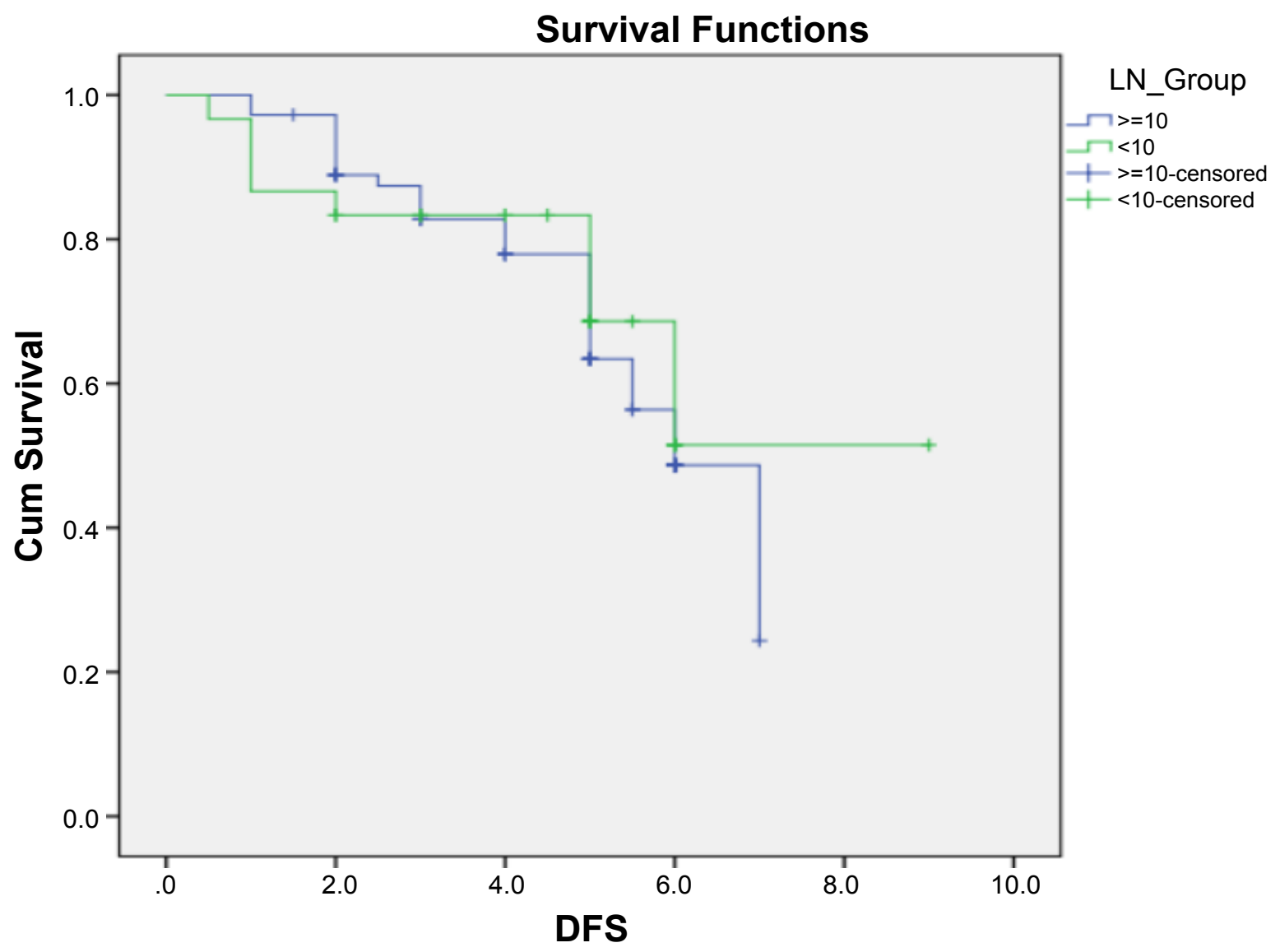

Figure 1: Disease free survival for patients in both arms.

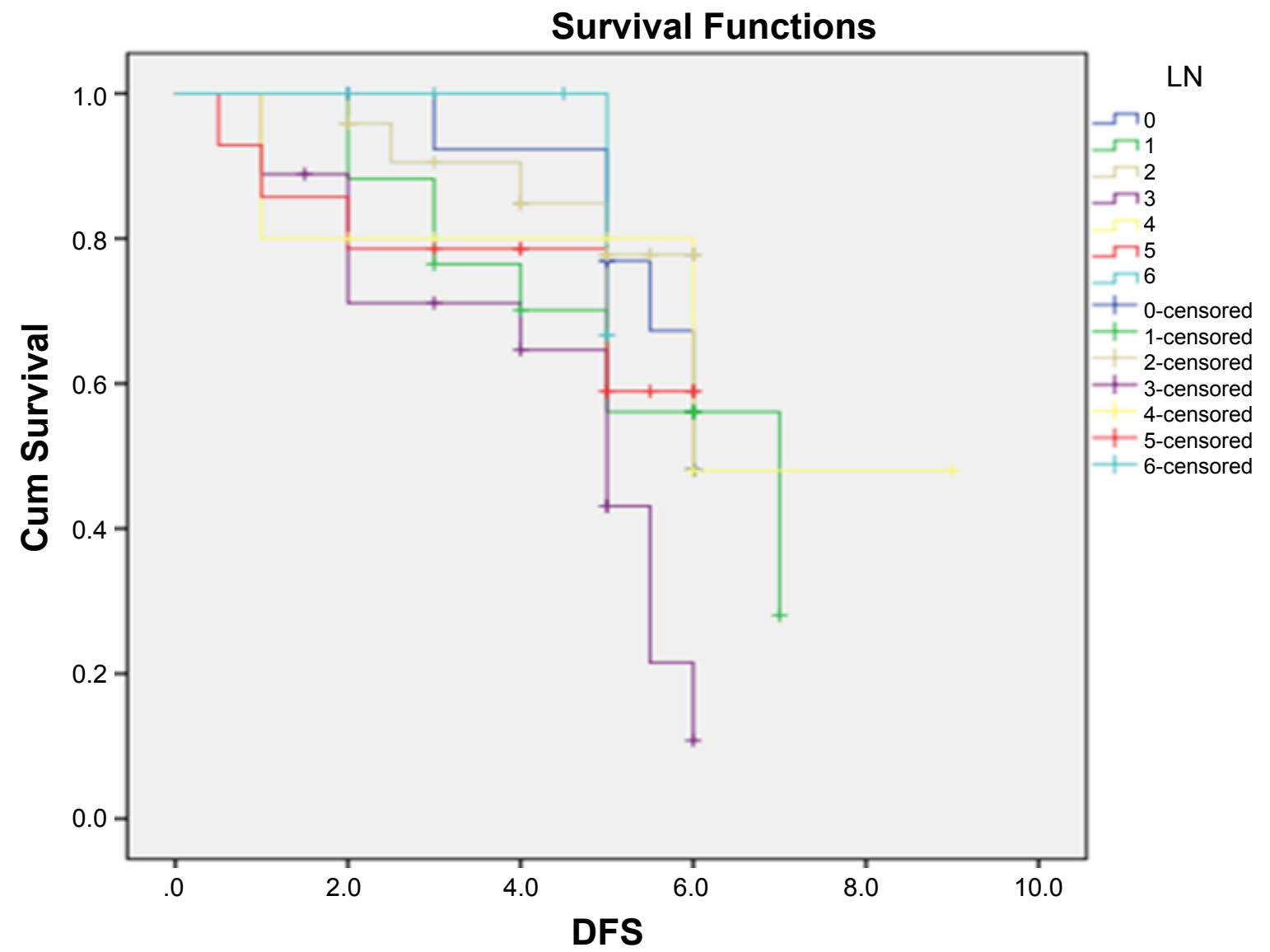

Figure 2: Disease free survival for all patients according to $L N$ distribution. 


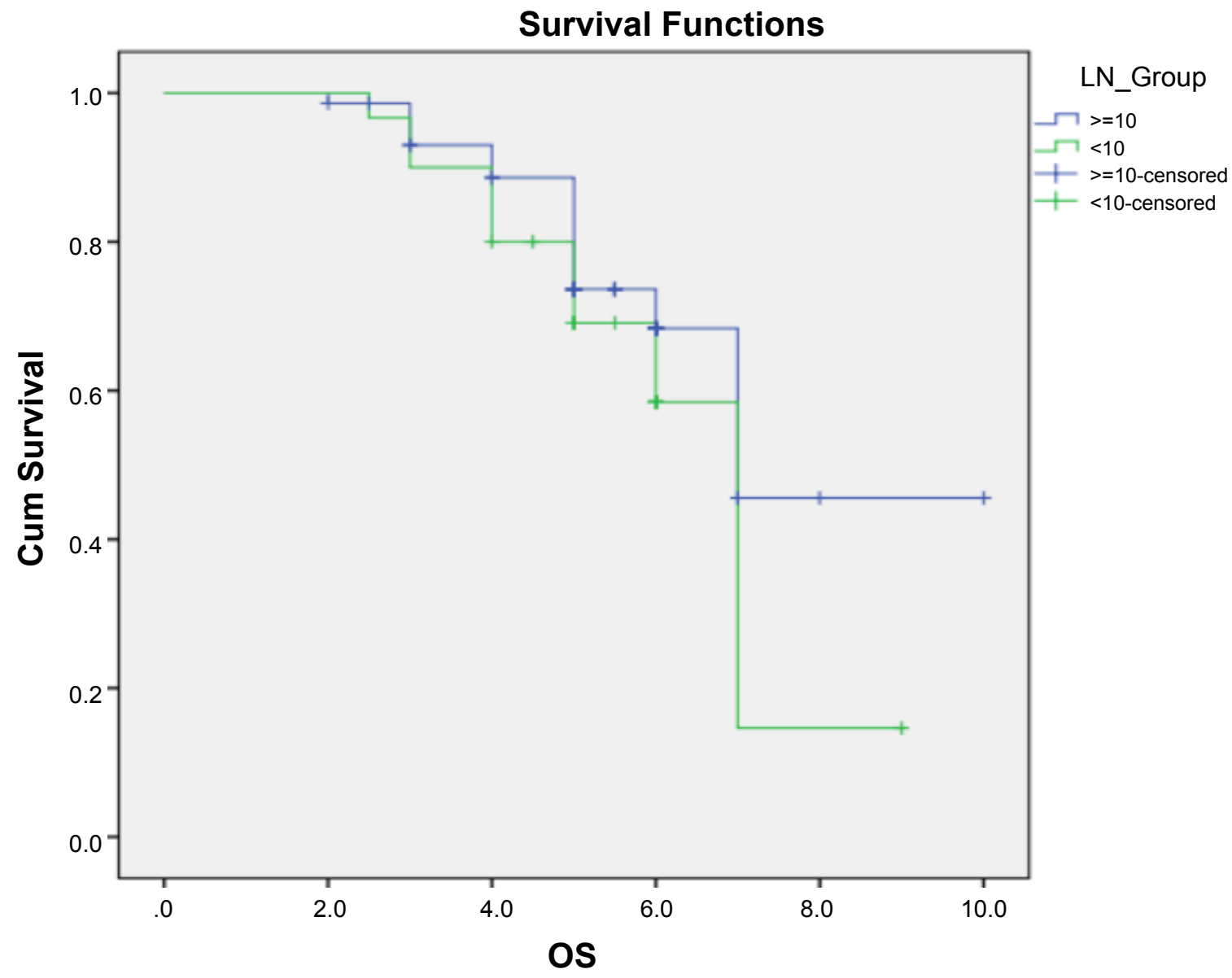

Figure 3: Overall survival for patients in both arms.

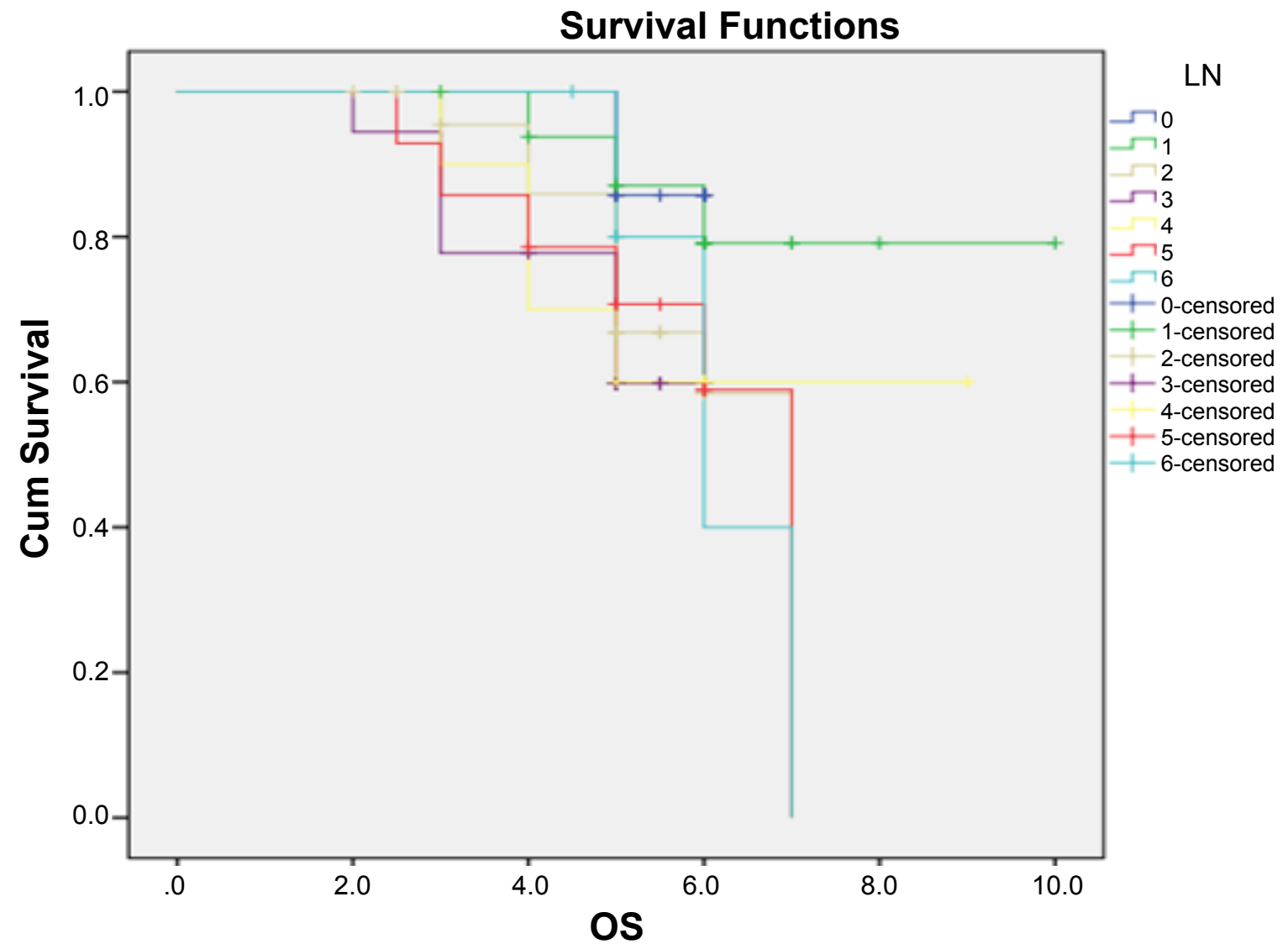

Figure 4: Overall survival for all patients according to $L N$ distribution. 
Table 4: Pattern of failure in both groups.

\begin{tabular}{|l|l|l|l|}
\hline Item & $\begin{array}{l}\mathbf{L N}=\mathbf{0 , 1 , 2 , 3} \\
\text { “n = 73” }\end{array}$ & $\begin{array}{l}\mathbf{L N}=\mathbf{4 , 5 , 6} \\
\text { “n = 30” }\end{array}$ & P-value \\
\hline Local Recurrence & $3(2.9 \%)$ & 0 & P value 0.64 \\
\hline Local and Distant metastasis & $3(2.9 \%)$ & $2(1.9 \%)$ & \\
\hline Distant metastasis & $21(20.4 \%)$ & $10(9.7)$ & \\
\hline No progression & $46(44.7 \%)$ & $18(17.5 \%)$ & \\
\hline
\end{tabular}

Table 5: Incidence of Lymphedema in both groups.

\begin{tabular}{|l|l|l|l|}
\hline Item & $\begin{array}{l}\text { LN = 0,1,2,3 } \\
\text { “n= 73” }\end{array}$ & $\begin{array}{l}\text { LN = 4,5,6 } \\
\text { “n=30” }\end{array}$ & P-value \\
\hline No Lymphedema & $25(24.3 \%)$ & $23(22.3 \%)$ & P value 0.000 \\
\hline Mild Lymphedema & $25(24.3 \%)$ & $7(6.7 \%)$ & \\
\hline Moderate Lymphedema & $17(16.5 \%)$ & 0 & \\
\hline Severe Lymphedema & $6(5.8 \%)$ & 0 & \\
\hline
\end{tabular}

As regard failure site there was no statistically differences between both arms with (P: 0.507) (Table 4).

Regarding Lymphedema There was highly significant difference between both arms $p$ value 0.000 , with higher grades in arm I (Moderate 17 cases and 6 cases severe edema (Table 5).

\section{Discussion}

Median PFS for patients having more than $10 \mathrm{LN}$ excised was 5.19, 4.77, 4.14, 3.69 years for N0, N1, N2, N3 respectively. While in the group with less than $10 \mathrm{LN}$ excised PFS was 4.5, 4.14, and 4.08 years (for N4, N5, and N6 respectively) with no significant difference between both groups (P: 0.290). Median OS for patients having more than $10 \mathrm{LN}$ excised was 5.57, 5.94, 4.97, 4.61 years for N0, N1, N2, N3 respectively, while in the other group having less than $10 \mathrm{LN}$ excised OS was 5.4, 5.14, 5.14 years (for N4, N5, N6 respectively) with non-statistically significant difference (P:0.117). Although there was no significant difference in local control rate in our study, patients with less dissected axillary lymph nodes has marginally lower control rates, while there is no survival difference in both arms. That was in agreement with the two large meta-analyses previously published. Firstly, Clarke 2005 In Early Breast Cancer Trialists Group, a meta-analysis of individual data revealed that axillary clearance versus effective axillary RT involved a little absolute difference $(<10 \%)$ in five-year risk of local recurrence, as well as little difference in breast cancer mortality [12].

The second meta-analyses were by Bromham, 2017; ten trials involving 3849 participants compared no axillary surgery versus axillary dissection. It showed no important differences between overall survivals of patients in the two groups (HR 1.06, 95\% confidence interval (CI) 0.96 to 1.17) [13]. As regard locoregional recurrence, it was higher with no axillary surgery (HR ranging from 1.10 to 3.06; 20,863 person-years of follow-up; four studies). It was uncertain whether no surgery increased the risk of distant metastasis compared with ALND (HR $1.06,95 \% \mathrm{Cl} 0.87$ to $1.30 ; 946$ participants; two studies). In our study both groups were more or less equally distributed except no higher $\mathrm{T}$ in arm 2, and less number of extranodal extensions in less dissected axillary lymph nodes arm, and that was correlated with that data from Melissa P [14], and Priyanka S, Omission of ALND should be applied cautiously in patients with tumors larger than $5 \mathrm{~cm}$ or gross extranodal extension, since these patient groups were not included in the aforementioned clinical trials 8 . Regarding quality of life, patients with less dissected axillary lymph nodes suffered significantly less from higher grade lymphedema that matches the results of Bromham, et al. 2017 in which no axillary surgery decreased the risk of lymphedema compared with ALND (OR $0.31,95 \% \mathrm{Cl} 0.23$ to $0.43 ; 1714$ participants; four studies) [13].

\section{Conclusion}

We found no significant OS or DFS differences with higher LN dissection compared with less LN dissection, but this needs further prospective studies.

The omission of axillary dissection in early breast cancer has no negative impact in local control or survival and should be cautiously used in patients with locally advanced disease or in presence of extracapsular spread. Quality of life was better for the less axillary dissected patients due to significantly lower incidence of advanced grade lymphedema.

Future work should evaluate techniques of radiotherapy and quality of life including lymphedema for both groups probably we can get a final answer for best management of axillary lymph nodes without compromising patients' survival and better quality of life.

\section{Data Availability}

Data availability will be according to university regulation. 


\section{Funding}

Authors did not receive any funding for the current study.

\section{References}

1. Yanxia Li, Earle H, Karan S, Kevin A, Anna S, et al. (2012) The prognostic value of lymph node cross-sectional cancer area in node-positive breast cancer: A comparison with $\mathrm{N}$ stage and lymph node ratio. Pathology Research International 2012.

2. Carter CL, Allen C, Henson DE (1989) Relation of tumor size, lymph node status, and survival in 24,740 breast cancer cases. Cancer 63: 181-187.

3. McCready DR, Hortobagyi GN, Kau SW, Smith TL, Buzdar $A U$, et al. (1989) The prognostic significance of lymph node metastases after preoperative chemotherapy for locally advanced breast cancer. Arch Surg 124: 21-25.

4. Overgaard M, Nielsen HM, Overgaard J (2007) Is the benefit of postmastectomy irradiation limited to patients with four or more positive nodes, as recommended in international consensus reports? A subgroup analysis of the DBCG 82 b\&c randomized trials. Radiother Oncol 82: 247-253.

5. Poortmans PM, Collette S, Kirkove c, Van Limbergen E, Budach V, et al. (2015) Internal mammary and medial supraclavicular irradiation in breast cancer. New England Journal of Medicine 373: 317-327.

6. Ashlyn S Everett, Drexell Hunter Boggs, Jennifer F De Los Santos (2018) Postmastectomy Radiation Therapy: Are We Ready to Individualize Radiation? International Journal of Breast Cancer 2018.
7. Fisher B, Montague E, Redmond C, Barton B, Borland $D$, et al. (1977) Comparison of radical mastectomy with alternative treatments for primary breast cancer. A first report of results from a prospective randomized clinical trial. Cancer 39: 2827-2839.

8. Fisher B, Jeong JH, Anderson S, Bryant J, Fisher ER, et al. (2002) Twenty-five-year follow-up of a randomized trial comparing radical mastectomy, total mastectomy, and total mastectomy followed by irradiation. N Engl J Med 347: $567-$ 575.

9. NCCN (2018) Clinical Practice Guide Lines in Oncology, invasive breast cancer.

10. Giuliano AE, Ballman KV, McCall L, Beitsch PD, Brennan MB, et al. (2017) Effect of Axillary Dissection vs No Axillary Dissection on 10-Year Overall Survival Among Women With Invasive Breast Cancer and Sentinel Node Metastasis: The ACOSOG Z0011 (Alliance) Randomized Clinical Trial. JAMA 318

11. SABCS 2018: AMAROS Trial: $10-$ Year Follow-up of Axillary Radiotherapy or Surgery in Early-Stage Breast Cancer.

12. Clarke M, Collins R, Darby S, Davies C, Elphinstone P, et al. (2005) Effects of radiotherapy and of differences in the extent of surgery for early breast cancer on local recurrence and 15 year survival: an overview of the randomized trials. Lancet 366: 2087-2106.

13. Bromham N, Schmidt Hansen M, Astin M, Hasler E, Reed MW (2017) Axillary treatment for operable primary breast cancer. Cochrane Database of Systematic Reviews.

14. Mitchell MP, Sharma P (2018) In The Use of Surgery and Radiotherapy as Treatment of Regional Nodes in Breast Cancer Patients. Oncology 32. 